\title{
QUEBRANTOS, BÚSQUEDAS Y AZARES DE UNA PASIÓN NACIONAL (DOS DÉCADAS DE NARRATIVA MEXICANA: 1970-1980)
}

\author{
POR
}

ARALIA LóPEZ GONZÁLEZ

Universidad Autónoma Metropolitana, Iztapalapa

\begin{abstract}
La novela es una pregunta que no puede ser contenida en una sola respuesta, porque es social, y la sociedad somos muchos. La novela es una respuesta literaria que nos dice siempre: el mundo se está haciendo y no puede ser detenido por una sola forma hegemónica de lenguaje.

Carlos Fuentes
\end{abstract}

\section{INTRODUCCIÓN}

Caracterizar dos décadas de narrativa mexicana, la de los setenta y los ochenta, implica también pensar en los cincuentay los sesenta para contextualizar culturaly sociohistóricamente una producción que no se da en el vacío y que, en muchos aspectos, como podrá apreciarse, supone una "cierta"continuidad con respecto al pasado.

Pierre Bourdieu (véase Problemas del estructuralismo, 1967) nos permite pensar esto mediante el concepto teórico y metodológico de "campo intelectual", que supone la autonomía relativa de la producción del llamado capital simbólico en una determinada cultura, en un espacio y tiempo específicos. La delimitación de un campo intelectual implica la comprensión de un área que posee un conjunto de normas a partir de las cuales se define su legitimidad. La constitución de un campo intelectual relativamente autónomo en torno a la creación literaria, supone agentes e instituciones que proveen los criterios de legitimidad cultural. Uno de los problemas más importantes para pensar y comprender las décadas de los setenta y los ochenta es, precisamente, el de la vacilación de criterios, la dificultad para definir lo que es o no es literatura.

La vacilación se manifiesta porque se trata de la producción de obras que rompen los límites de los géneros literarios, a veces por la gran mezcla de los mismos, haciendo muy difícil su clasificación. Y también porque resulta difícil distinguir, entre tanta producción, el valor de la misma en cuanto se aleja de los criterios canónicos. Es ilustrativo al respecto el debate provocado a partir de dos éxitos de venta espectaculares (comerciales) para el medio mexicano. Ellos son Arráncame la vida (Ángeles Mastretta 1985), y Como agua para chocolate (Laura Esquivel 1989). ${ }^{1}$

\footnotetext{
${ }^{1}$ En general, existe recelo al juzgar la narrativa escrita por mujeres en la década del ochenta, pues su gran cantidad ha constituido lo que ya se conoce desdeñosamente como boom femenino. Esta
} 
De acuerdo con lo dicho por Bourdieu con respecto al "campo intelectual", no hay duda de que a partir de los cincuenta, éste comienza a delimitarse claramente. Los escritores se profesionalizan, las instituciones literarias adoptan una fisonomía más formal, surge un espacio crítico consistente en el suplemento cultural de Novedades con "México en la cultura", que dirige Fernando Benítez durante 1949-1961, fuente obligada para el estudio de la producción literaria de $1950 .{ }^{2}$ Carlos Fuentes y Emmanuel Carballo fundan la Revista Mexicana de Literatura (1955-58). Juan José Arreola — pionero de los talleres literarios de los setenta-, dirige un Tallery promueve a los jóvenes escritores por medio de las ediciones y la revista Mester. Vicente Leñero, Beatriz Espejo, Elena Poniatowska, Fernando del Paso, José Emilio Pacheco, Tita Valencia, Jorge Arturo Ojeda, José Agustín y muchos otros pasaron por este Taller, grupo y espacio de formación y difusión que junto con el grupo de Juan García Ponce (Generación de la Casa del Lago, entre otros Salvador Elizondo, Juan Vicente Melo, Tomás Segovia, Inés Arredondo, etc.), fueron los puntos visibles del activismo literario de la época. ${ }^{3}$ Es ya por entonces, cuando el trabajo intelectual y artístico comienza a especializarse, al mismo tiempo que surge un mercado para sus obras. Esto es lo que permite una cierta autonomía de la actividad creadora manifestada, en principio, por una mayor preocupación por los aspectos estéticos más que por los históricos, sociales o políticos. De acuerdo con lo dicho hasta aquí, lo que me parece más destacable es el surgimiento de un mercado para los bienes simbólicos, "institución" que desde entonces irá interviniendo cada vez más en los hechos literarios y formando parte del "campo intelectual”,

producción hace pensar a los más en un fenómeno comercial y no tanto en una creación de buena ley. Sin embargo, en esto influyen también los prejuicios sexistas y el rechazo o no comprensión de ciertas corrientes críticas actuales, entre ellas la culturalista y la feminista. Las mismas escritoras participan de estos prejuicios e incluso, la crítica académica parece tener dificultades para tratar, en general, las no canónicas producciones de este período.

${ }^{2}$ Posteriormente Benítez continúa la dirección de este espacio crítico en "La cultura en México", de la Revista iSiempre!, también fuente fundamental para el estudio de la producción literaria de 1960. Benítez es significativo en muchos sentidos porque reescribe novelísticamente la historia de México desde la perspectiva de instituciones sociales como el caciquismo (El agua envenenada, 1961) o el período presidencial de Carranza (El rey viejo, 1960). En su visión se mezclan el historiador, el periodista, el crítico político y literario, el creador de ficción, para escribir obras ensayísticas como Los indios de México (1961-1981) y Lázaro Cárdenas yla Revolución Mexicana (1977). Este escritor es, un antecedente obligado para juzgar el proceso de hibridación genérica de la novela.

${ }^{3}$ No quiero dejar de subrayar la importancia que tuvo por los cincuenta la publicación de El laberinto de la soledad ( $\mathrm{Paz} 1950$ ), porque en lo conceptual continuaba la reflexión psicológica y ontológica - cultural en términos generales - sobre la identidad del mexicano, iniciada por Samuel Ramos en El perfil del hombre y la cultura en México (1934). Este tema, desde la misma perspectiva filosófica y cultural, siguió siendo tratado por el Grupo Hyperión, constituido por Leopoldo Zea y Luis Villoro. Más tarde fue pensado psicoanalíticamente en El mexicano, psicología de sus motivaciones (Santiago Ramírez 1959) y, hoy en día, mezclando la imaginación literaria con la perspectiva de los estudios culturales, tiene su gran expresión "posmoderna" en el antropólogo Roger Bartra (La jaula de la melancolía, identidady metamorfosis del mexicano, 1987). Nadie ignora, desde luego, la importancia que El laberinto de la soledad tuvo en los escritores de los cincuenta y los sesenta, particularmente en Carlos Fuentes. 
incluso como factor dominante. A propósito de todo esto, y para expresar las líneas de pensamiento que adopto en este trabajo, me valgo de la cita siguiente:

El campo intelectual constituye el principio mediador por excelencia en aquellas sociedades donde la producción de bienes simbólicos se ha configurado como dominio relativamente autónomo. (...) El campo intelectual opera, además, sobre cada miembro devolviéndole una imagen pública de su obra - su valor, su verdad, etc.-, con la que el creador debe ajustar cuentas, necesariamente, asi sea para rechazarla.

Artista "oficial" o de "vanguardia", intelectual "integrado" o "marginal", su posición dentro del campo intelectual define el tipo de participación en el "capital" cultural de una sociedad en un momento dado. Este patrimonio no es sino el conjunto de problemas y temas, modos de percibir y de razonar, hábitos mentales y códigos retóricos comunes a una sociedad y que hacen posible la comunicación cultural dentro de ella. Trasmitido a través de mecanismos diversos - la escuela es uno de ellos-, dicho "capital simbólico" constituye algo así como la infraestructura implícita de los mensajes culturales, que éstos eliden porque estásobrentendida. La cultura, entonces, no se añade como una determinación exterior a una intención creadora madurada independientemente del campo intelectual en que está inscrita. Una intención se especifica como proyecto intelectual concreto, objetivado en obras particulares, a través de la dialéctica que se establece entre sus exigencias y el campo intelectual (con su correspondiente patrimonio simbólico) del que forma parte (Altamirano y Sarlo 15 y 16).

\section{El CAMPO LITERARIO}

Al revisar la nómina de autores y obras del período de 1970 y 1980 , lo primero que salta a la vista es la necesidad de distinguir entre los escritores que desde 1940 ó 1950 empezaron a construir el edificio de la novela mexicana moderna - cuyo pionero fue Mariano Azuela - que siguieron escribiendo en los setenta e incluso en los ochenta; y los escritores jóvenes en términos cronológicos, que nacieron después de 1940. Asimismo, si los historiadores de la literatura mexicana marcan un cambio en el desarrollo de la novela a finales de los cuarenta, cuyo rasgo específico es la ruptura con la estética de la representación realista $\mathrm{y}$, en lo temático, el desplazamiento de lo rural a lo urbano y de lo social a lo individual; en los 60 ocurre otro cambio: 1967 es el inicio del boom literario latinoamericano; y, en lo histórico y en lo simbólico, 1968 es un año que representó para México un parteaguas a raíz de la Matanza de Tlatelolco ( 2 de octubre).

La primera gran promoción de narradores mexicanos modernos, padres de la nueva narrativa de ficción después del ciclo literario de la Revolución Mexicana son, como todos sabemos, Agustín Yañez (1904-1980), José Revueltas (1914-1976), Juan Rulfo (19181986) y Juan José Arreola (1918). La segunda gran promoción, según Christopher Domínguez (Antologia de la Narrativa mexicana del siglo XX, T. 2, 1991: 11), es la que nació por los años treinta y su guía más visible fue Carlos Fuentes, a quien habría que unir con Gabriel García Márquez - de acuerdo con José Emilio Pacheco-, ya que el escritor colombiano llegó a México en julio de 1961 incorporándose al grupo de escritores que, con Carlos Fuentes, estimulaban el ambiente cultural de los sesenta. No debe olvidarse tampoco la sombra tutelar de Julio Cortázar. De este mismo grupo hablan Domínguez y Pacheco reconociéndolo, uno, como "los iconoclastas" y, otro, como la "generación perdida". Ambos críticos, sin embargo, coinciden en que sus participantes fueron los dinamizadores 
y los renovadores radicales de la ficción narrativa en México. El liderazgo cultural de los 60 corresponde a este grupo del cual Pacheco dice lo siguiente:

Por un tiempo García Márquez fue uno más de esa generación mexicana —ella sí la única y verdadera "generación perdida" de este siglo- que iluminó una época breve (19621968) enmarcada entre dos crímenes: el asesinato de Rubén Jaramillo y la matanza de Tlatelolco (465).

Más adelante, da el crédito a ese grupo conocido también como "La Mafia"-novelado en 1967 por Luis Guillermo Piazza en la obra del mismo título y por René Aviles Fabila en Los juegos, ${ }^{4}$ pero vitalizador de la narrativa mexicana al mismo tiempo que su gran representante, Carlos Fuentes, la incorporaba al ámbito continental del "boom".

Por otra parte Domínguez, caracterizando los sesenta, habla de este grupo y de la promoción en general, así:

En 1958 Juan García Ponce gana con una obra de teatro el Premio de la Ciudad de México. A los veinte años aparecen José Emilio Pacheco, hombre de letras que acabará por suceder y superar a Alfonso Reyes; Carlos Monsiváis, personalísimo cronista y crítico de la cultura, que toma un compromiso que Salvador Novo se negó a contraer; José Agustín, precoz abanderado de una nueva novela. Los jóvenes pintores, acaudillados por Cuevas, rompen festivamente con el esclerótico dogmatismo de los muralistas. Renovación en el teatro y en el cine. Años de la Revolución cubana. Fernando Benítez cuestiona al gobierno y acoge a los jovenes. Salvador Elizondo hace crítica de cine, funda la revista s.nob y reaparece como gran novelista. Huberto Batis y Carlos Valdés dirigen Los cuadernos del viento. Estimulados por Jaime García Terrés, Tomás Segovia y Juan Vicente Melo toman revistas y recintos universitarios. Inés Arredondo, Vicente Leffero, Fernando del Paso, Julieta Campos, Homero Aridjis, Augusto Monterroso, José de la Colina, Gustavo Sainz, Sergio Fernández, José Carlos Becerra, Juan Tovar, Elena Poniatowska, Esther Seligson, Sergio Pitol, Jorge Ibargüengoitia, Luisa Josefina Hernández: México tenía la más rica, diversa y estimulante de sus promociones literarias ( 31 y 32 ).

De lo dicho por Domínguez se desprende el dinamismo de los sesenta, en los cuales también se fundaron las editoriales Era (1960) y Joaquín Mortiz (1962), y se publicó el Diccionario de escritores mexicanos (1967). Muchos de los autores consignados por Domínguez aún siguen escribiendo e, incluso, han producido excelentes obras entre 1970 y 1980 como del Paso, Poniatowska, Monsiváis, Pitol, Leñero, Sainz, etcétera. Abundando en la caracterización de la época de los sesenta el mismo crítico dice lo siguiente:

\footnotetext{
${ }^{4}$ Por los 70 y 80 , en esta misma tendencia a tratar como tema y como problema el ambiente cultural, sus protagonistas y grupos, ya abordados irónica o satíricamente, ya reflexionados con más rigor, destacan las siguientes obras: El tañido de una flauta (Sergio Pitol 1972), Y te sacarán los ojos (Salvador Mendiola 1974), ¿ABCDErio O ABeCeDamo? (Daniel Leyva 1980), y llamo la atención sobre los finales ¿Rio o amo?; Cuadernos de Gofa (Hugo Hiriart 1981). En otro sentido, Compadre Lobo (Gustavo Sainz 1977) es una reflexión seria sobre la condición personal del escritor o del artista en general; Parejas (Jaime del Palacio 1981), novela en clave en la que se aborda nostálgicamente una época y sus protagonista culturales, etcétera.
} 
Iconoclastia ante el poder, desenfado ante la tradición nacionalista, entrega a la vocación artística sobre todas las cosas, el fervoroso espiritu comunitario, son algunas de las características de una generación que gozó como pocas de las consecuencias vitales tanto como tanáticas de su experiencia. A su lado, la vida de los Contemporáneos, sus ilustres precursores, suena opaca, triste y difícil. Dos conflictos políticos abren y cierran los años dorados de la promoción. En 1961 Fernando Benítez es expulsado de la dirección de "México en la cultura" (suplemento dominical de Novedades) y es acogido en iSiempre! donde continúa su labor como núcleo activo de los jovvenes escritores. En 1967 Gastón García Cantú agrede, con bajos argumentos puritanos y nacionalistas, a Melo, García Ponce, De la Colina y al director teatral Juan José Gurrola, que ocupaban posiciones claves en la difusión cultural universitaria. Una renuncia masiva puso fin al estimulante dominio que "la mafia" ejercía sobre la cultura mexicana, justamente en los años de cerrazón política y xenofobia estatal que culminaría en el movimiento estudiantil de 1968 ( 35 y 36 ).

Como puede apreciarse, tanto Pacheco como Domínguez coinciden en otorgarle presencia animadora a esta promoción durante seis años aproximadamente: desde 1961 ó 1962 hasta 1968 —año incuestionable para ambos. Los setenta, en mi opinión, empiezan también en este año y, literariamente, se inauguran con El apando (1969) de José Revueltas, Hasta no verte Jesús mio (1969) y La noche de Tlatelolco (1971) de Elena Poniatowska.

\section{PRIMER PARÉNTESIS}

Pero antes de seguir adelante, es conveniente subrayar que, en los sesenta, "la chaviza"5 mostró su credencial tanto de sujeto social como de objeto literario, reclamando su derecho de representación en la "alta" cultura, y reclamándolo precisamente con la irreverencia de una visión y un lenguaje que profanaba su santuario. José Agustín y Gustavo Sainz, escriben respectivamente La tumba (1964) y Gazapo (1965), novelas en las cuales los protagonistas son adolescentes que imponen una especie de sub-cultura o contracultura con base en la música rock, los teléfonos, las grabadoras, la liberación sexual y verbal, el antinacionalismo en pro de la pertenencia urbana barrial y de la norteamericanización. El fin de este festival guasón y patético — revolución cultural también—, termina según Domínguez en 1973 con la novela Se está haciendo tarde (final en laguna), de José Agustín. Éste y Sainz tuvieron seguidores en Juan Tovar, René Avilés Fabila, Gerardo de la Torre, Héctor Manjarrez, incluso Luis Zapata. Todos, fuera de la Onda, continuaron escribiendo.

\section{SEgundo PARÉnTESIS}

En la misma década surgen dos novelas que son, para algunos críticos, las mejores: Farabeuf (1965) de Salvador Elizondo y Morirás lejos (1967) de José Emilio Pacheco, obras queya se caracterizan por el manejo de la metaficción o autorreferencialidad narrativa. Yo agregaría, además, José Trigo (1966) de Fernando del Paso, novela difícil en la que se mezclan los géneros con la construcción de un lenguaje alucinantemente hermoso y complejo, y cuya estructura laberíntica exige del lector una verdadera co-autoría. En ella el neobarroquismo se exhibe en todo su esplendor a la manera de sus "grandes" como

\footnotetext{
${ }^{5}$ Así se les dice en México a los jóvenes casi adolescentes.
} 
Asturias, Carpentier o Lezama Lima. Esta novela tiene para mí, en lo particular, una enorme importancia política y social porque literaturiza, entre otras cosas, la huelga ferrocarrilera que alude a la de 1959 y constituye - aunque no sea únicamente eso- la novela proletaria de más alto rango artístico que se ha escrito, quizá, en Latinoamérica. No menos importante es el hecho de que en la misma, se representan los orígenes históricos de la Ciudad de México, así como su transformación moderna a partir del barrio de obreros ferrocarrileros que, debido a los disturbios laborales, el gobierno decidió hacer desaparecer construyendo los modernos edificios de Tlatelolco. De barrios a colonias, ${ }^{6}$ la fisonomía y el sentido humano del vecindario va en retirada. La zona elegida por del Paso es de enorme significación histórica para la Ciudad de México.

\section{TERCER PARÉNTESIS}

No quiero dejar de subrayar la presencia de las mujeres como autoras y protagonistas en la narrativa de los sesenta. Primero que nada, es importante recordar que a fines de los cincuenta se publica esa gran novela que es El libro vacio (1958), de Josefina Vicens (19151988). Es en esta obra, de avanzada sin duda, donde aparece antes que en Farabeufo en Morirás lejos, el tema y la técnica de la autorreferencialidad: la narración que se cuenta a sí misma; se desarrolla el primer personaje que muestra los claros efectos de una sociedad anómica: y donde comienza, también, el silencio del que habla Sara Sefchovich a propósito de esta tendencia autorreferencial en Fuentes, Elizondo o Pacheco:

La apertura democrática en la política es la clausura novelesca. Como si el exceso de ruido y gente que habitó a la narrativa desde la Revolución hasta los sesenta, hubiera cansado ya a los escritores. Como si el discurso oficial que parecía decir algo, en realidad no dijera nada. Como si las preocupaciones por contar algo se hubieran desvanecido. Ahora se buscaba el silencio (con la palabra), la preocupación por la nada (con la experiencia creativa) hasta generar una narrativa "de la creación creándose" como le llamó Claude Fell. Así pues, lo importante es la forma, las técnicas, los montajes y sobre todo la autorreferencia, es decir, se trata de la narrativa del yo por excelencia (206 y 207).

Lo que me importa señalar ahora es que a fines de los cincuenta y principio de los sesenta las mujeres junto con la "chaviza" hacen su aparición consistente como nuevos sujetos sociales en la literatura. Las narradoras Elena Poniatowska con Lilus Kikus (1954); Rosario Castellanos (1925-1974) con Balún-Canán (1957), Ciudad Real (1960) y Oficio de tinieblas (1962); Luisa Josefina Hernández con El lugar donde crece la hierba (1959); y Elena Garro con Los recuerdos del porvenir (1963) y La semana de colores (1964), son los nombres y obras pioneros de la narrativa mexicana contemporánea escrita por mujeres, la misma que tiene su "boom" en los ochenta. En términos de una reflexión feminista de la literatura, por razones que ya he argumentado en otros trabajos, se destaca Rosario Castellanos (véase López "Utopía creativa y acción").

\footnotetext{
${ }^{6}$ El sustantivo colonia sustituye, en México, al de barrio; pero urbanísticamente significa fenómenos diferentes. En el barrio existe una memoria colectiva, un reconocimiento mutuo entre sus habitantes, y vínculos de arraigo y solidaridad. La colonia es ya un espacio urbano más indiferenciado que responde casi siempre a cálculos y políticas demográficas.
} 
La producción femenina que, desde la perspectiva de la crítica feminista plantea una problemática particular dentro del conjunto de las literaturas nacionales, está siendo estudiada en el Programa Interdisciplinario de Estudios de la Mujer, El Colegio de México. Como ya lo mencioné anteriormente, dos obras en los ochenta se convierten en best-sellers, hecho poco común en la historia del mercado literario mexicano: Arráncame la vida y Como agua para chocolate. El éxito de ventas de estas novelas ha inducido a pensar que se trata de literatura "light" - término nuevo en la jerga literaria del país -; es decir, que se trata de una literatura comercial más que de obras "buenas" y respetables desde el enfoque de la "alta" cultura, evidentemente patriarcal. A partir de este fenómeno, resulta obvio que el mercado es ya un elemento determinante en el campo intelectual. Es necesario, pues, plantear y definir nuevos criterios para juzgar teórica y críticamente los hechos que pertenecen a la alta cultura, a la cultura de consumo o de masas y a la cultura popular auténtica. Así como la pertinencia de estas clasificaciones en la actualidad. Lo que sí se evidencia ya es la existencia de una situación vacilante en cuanto a las interpretaciones del hecho literario. O dicho de otra manera: se evidencia un conflicto entre la institución literaria tradicional y académica con la poderosa "institución" que es el mercado, insinuándose tal vez que esta última pueda resultar dominante, desintegrando de alguna manera la noción de canon así como sus presupuestos.

De cualquier manera, la narrativa de los setenta y de los ochenta no puede prescindir de esta autoría femenina cuyos nombres más relevantes junto con los ya mencionados son, entre otros, los de Margo Glantz, Julieta Campos, María Luisa Mendoza, Angelina Muñiz, María Luisa Puga, Esther Seligson, Aline Petterson, Ethel Krauze, Bárbara Jacobs, Beatriz Espejo, Silvia Molina, Carmen Boullosa, Brianda Domecq y, evidentemente, Mastretta y Esquivel. No ignoro que dejo de mencionar otras autoras importantes, pero basten las anteriores para mostrar la vitalidad de las mujeres como protagonistas de la narrativa mexicana en las décadas sobre las que estamos reflexionando. Los personajes femeninos creados por ellas ya forman una rica galería en el conjunto de la literatura nacional. Mencionemos a algunos: Catalina Díaz Puiljá (Castellanos, Oficio..., 1962); Isabel o Mariana (Garro, Los recuerdos..., 1963 y Testimonios sobre Mariana, 1981); Jesusa Palancares (Poniatowska, Hasta..., 1969); Ausencia (Mendoza, De Ausencia, 1974); Susana (Puga, Pánico o peligro, 1983); Catalina Guzmán de Ascencio (Mastretta, Arráncame..., 1985); Tita (Esquivel, Como agua..., 1989); y Teresita Urrea (Domecq, La insólita historia de la santa de Cabora, 1990), entre otros.

DigRESIÓN NECESARIA: "MILAGRO", BOOM Y POSBOOM

Para seguir reflexionando sobre los setenta, recordemos antes que desde 1943 en la novela también innovadora, El luto humano, de Revueltas, se plantea que la Revolución Mexicana y sus proyectos sociales han muerto sin que se hayan cumplido sus objetivos. Es con esta novela con la que se pone fin, según algunos críticos, al ciclo de la Novela de la Revolución, y no con Al filo del agua (1947), de Agustín Yañez. Ya en los cuarenta se ha consolidado definitivamente la institucionalización de la Revolución, y su programa central de reivindicación popular y social va desplazándose hacia objetivos eminentemente 
capitalistas que culminan en la gestión presidencial de Miguel Alemán entre 1946-1952. E1 crecimiento económico, la industrialización, la transformación de una cultura básicamente rural o preindustrial en otra urbana y tecnológica, son metas a conseguir aún a costa de la dependenciadel país de los capitales extranjerosy de la transnacionalización en general. Por eso, en cuanto a lo literario, José Joaquín Blanco dice en 1982:

El asunto fundamental de la literatura mexicana en la segunda mitad del siglo XX es la modernización del país, la brusca y forzada transformación de una Nación preindustrial, rural, campesina, con poderosas atmósferas indígenas, aparentemente aislada de la vida occidental y arraigada en modos tradicionales, en un pais industrial y urbano. (...) Los novelistas cierran el mundo mexicanista, indígena y rural, y se pierden en las vastas y caóticas dimensiones urbanas; (...) descubren estéticas modernas y se proponen ahondar en los destinos irrepetibles de personajes que aspiran a ser considerados ciudadanos del siglo XX. Los hechos sociales e históricos desgarrados se asumen frecuentemente como centros del debate, encarnando así -en los mejores casos-el inicio de una cultura civil donde una literatura se moderniza para alcanzar los grandes perfiles de un país que se expande (...), cambia. En tal sentido podría hablarse de la literatura de estas tres últimas décadas (1950-1980) sólo como el principio de una nueva cultura mexicana cuyo posterior trayecto resulta impredecible; y del que apenas se podrá apuntar que (estará) unido cercanamente a la vida y a la civilización industrial y urbanas de occidente, con conflictos económicos y sociales propios de ese marco [el subrayado es mío, 24].

Creo que lo anterior define bastante bien lo que ha venido sucediendo en la narrativa mexicana desde 1950. Si en 1943 Revueltas anuncia literariamente la muerte de la Revolución Mexicana, Rulfo la confirma en El llano en llamas (1953) y en Pedro Páramo (1955). Lo mismo Fuentes en La muerte de Artemio Cruz (1962), pasando antes por la creación de la gran urbe y la consolidación de la clase media mexicana en La región más transparente (1958). La modernización —que pretende borrar o por lo menos encubrir un México periférico y dependiente económicamente, un México que todavía contiene como parte fundamental de sí mismo otras etapas históricas, otras formaciones sociales ajenas al progreso capitalista y que también pretende ignorar su falta de desarrollo político en el sentido de su modelo democrático-, informará a la narrativa mexicana. De cualquier manera, las tres décadas que analiza Blanco se caracterizan por una creciente profesionalización del quehacer literario, por una preocupación consecuente con su óptima realización artística, y por la actualización, la equiparación $y$, al mismo tiempo, la diferenciación con las literaturas metropolitanas; coincide pues, en los sesenta, con la eclosión del "boom" narrativo latinoamericano que, a partir de 1970, se constituye en modelo para los jóvenes narradores del subcontinente haciendo visible, además, la existencia de una tradición literaria latinoamericana.

Para la mayoría de los críticos, el año clave en la literatura latinoamericana es 1967. Cien años de soledad conquista el mercado internacional. El mismo año, Miguel Ángel Asturias recibe el Premio Nobel; Vargas Llosa, el Rómulo Gallegos; Fuentes, el Biblioteca Breve. Vicente Leñero había ganado antes ese premio, en 1963, con Los albañiles (1964); y el escritor cubano Guillermo Cabrera Infante publica Tres tristes tigres, que gana también en 1964 el mismo premio. De esta novela se ha dicho que plantea un corte verbal entre el pasado y el futuro en el espacio literario latinoamericano, pues crea una especie de Spunish 
language que renueva al idioma castellano. El manejo del lenguaje en esta obra tiene semejanzas con los juegos lingüísticos que hacen los jóvenes onderos mexicanos prematura afición desconstructiva-; lo cual evidencia comunidades históricas, sociales y estéticas de época. Otra gran novela de esta década es Paradiso (1968), de José Lezama Lima (1910-1976), que constituye un brillantísimo ejemplo del refuncionamiento de la estética barroca - neobarroca-, desde la perspectiva y la sensibilidad americanas de los sesenta.

Así pues, en esta década se abren los mercados literarios del gran mundo para Latinoamérica. Sus puertas se hacen más amplias cuando por los 70 se concede el Nobel a Neruda; y el prestigio de nuestra literatura está consolidado entre 1980 y 1990 , cuando también se lo conceden a García Márquez y a Octavio Paz. Pero ya los mercados mundiales son más estrechos. Entre el premio de Asturias y el de Paz, se produce el fenómeno del boom, así como su debilitamiento, que da lugar al llamado posboom. Justamente las décadas de 1970 y 1980 ocupan la temporalidad de este proceso. ¿Cuándo empezó el posboom? Juan Manuel Marcos estima que su novela precursora es Yo el Supremo (1974), de Augusto Roa Bastos:
Autores de la nueva generación, desmantelando la tradición borgiana, socavando el narcicismo pequeño burgués, parodiando el discurso establecido, carnavalizando la palabra hegemónica (...) se encuentran hoy a la vanguardia de lo que provisoriamente se podría llamar el "posboom", un movimiento en que convergen la restauración poética del conflicto lingǘstico-cultural (...), la reprobación cervantista de patrones establecidos (...): más allá de las diferencias generacionales, estos nuevos autores comparten el compromiso para mostrar con un realismo sin simplificaciones basado en el arte compilatorio del habla coloquial, ya la revolución antisomocista (...) como ha hecho Antonio Skármenta, ya el callejón sin salida de la plutocracia bogotana que ha descrito Helena Araújo, ya la crisis interna del típico exiliado de los setenta que ha confesado con fuego y deslumbrante poesía callejera Mempo Giardinelli (11).

De acuerdo con Marcos, el posboom significa un regreso a las preocupaciones históricas, sociales y políticas en toda Latinoamérica. Volvamos pues a México en los sesenta. En la visión literaria de Revueltas, Rulfo y Fuentes, van apreciándose los signos sociales de una pérdida de consenso en cuanto al sistema político mexicano. Valga sólo señalar el desencanto de unos con la Revolución Mexicana; y el "encanto" de otros con la "modernización": el bienestar material en el que emergen visiblemente las manifestaciones de una sociedad de consumo que, más adelante, será ya de masas. En términos generales se observa una desnacionalización y despolitización paulatina de los valores, incluso en contradicción aparente con los lemas de la cultura oficial y, en algunos escritores una franca tendencia a la cosmopolitización por varias razones. Algunos nombres que la ilustran son: Juan García Ponce, Salvador Elizondo, Sergio Pitol, Juan Vicente Melo, Inés Arredondo (1928-1989), y otros. Sin dejar el ambiente provinciano, Sergio Galindo (1928-1992) explora la psicología de personajes solitarios, incomunicados, reprimidos. La onda, con otras características, también participa de esta modalidad.

México ha cambiado su proyecto de nación y su fisonomía cultural entre ilusiones de opulencia democrática y desilusiones de miseria feudal, cuando sobreviene el Movimiento Estudiantil de 1968 y la Matanza de Tlatelolco. Algunos escritores despiertan sobresaltados 
del sueño de neutralidad de la "alta" cultura e ingresan al laberinto de contradicciones nacionales. Muerte. Presos políticos: entre ellos Revueltas, que escribe El apando en prisión. Es necesario asumir una nueva actitud hacia la realidad y hacia la literatura. Esta quiebra la describe así Monsiváis:

En unas horas, el piadoso edificio de la seguridad se ha derrumbado. La comodidad de un país parecido al cuerno de la abundancia, la tranquilidad de saberse distinto al resto de América Latina, se anulan ante esa estridencia de las ambulancias, ante el frío anudado en la contemplación de las fuerzas policiales (Dias de guardar 224).

Los hechos del 68 ponen fin, casi también, al "milagro" económico mexicano que se venía desarrollando desde los cincuenta. En los setenta sobreviene un proceso inflacionario cuya consecuencia es la devaluación del peso. El país se enfrenta al desequilibrio y a la especulación, así como a la fuga de capitales. A pesar de algunos intentos de recuperación todo conduce a la pérdida de confianza en el gobierno y la crisis estalla definitivamente en 1982, cuando el presidente López Portillo considera que debe nacionalizar la Banca. "Frente a esta modernidad del desastre", como diría Blanco, se necesitarán nuevos autores. Elmismo crítico comenta los hechos y sus efectos durante 1950 a 1980 de un modo aún vigente:

Entre apocalipsis y cuernos de la abundancia, (...) empezó a plantearse la revolución mexicana críticamente (...). Fueron años de grave discusión (...). Y al mismo tiempo, de la continua revaloración de la democracia frente al fascismo sudamericano y de Centroamérica. En décadas tan convulsas, sólo en exóticas salas de conferencia y ciegos cubículos doctorales la literatura pudo dejar de tener que ver con la política (25).

\section{MARGINALIDAD Y MASIFICACIÓN, CLASE MEDIA, BURÓCRATAS Y EMPRESARIOS}

Pues bien, así las cosas, entramos a los setenta con El Apando, Hasta no verte Jesús mio y La noche de Tlatelolco. Entramos, quizás, prematuramente al posboom. En las dos primeras novelas, Revueltas y Poniatowska trabajan con ambientes y personajes marginales, afectados en todos los casos por la máxima represión-opresión de la miseria, la desigualdad y la injusticia social. Jesusa Palancares - otra forma de ser mujer muy ajena al estereotipo decretado por los esquema liberales para la familia burguesa - , se hace oír mediante cinta magnética que reelabora artísticamente Elena Poniatowska en su novela testimonial. En $E l$ Apando, asesinos, ladrones, drogadictos - la otra cara de la respetable sociedad-, exhiben su violencia y deformación vigilados por carceleros tan deformados como ellos. Revueltas logra aquí una alegoría de la sociedad represiva y sus consecuencias. En ambas novelas, violencia de todo tipo: vertical, entre dominados y dominadores; horizontal, entre iguales y oprimidos; interior, autocastigo y autodestrucción; verbal, en la expresión y en los contenidos, significados y significantes castigados, golpes de obscenidades que agreden el "buen gusto" y el orden convencional del lector común (véase Dorfman, Imaginación y violencia en América, 1970).

Estas obras - sin olvidar como antecedentes Los errores (1964) de Revueltas, Los albañiles (1964) de Leñero, Los hijos de Sánchez (1964) de Oscar Lewis o (pasando a otro lenguaje) el film Los olvidados (1950) de Buñuel-, pueden relacionarse con la tendencia, 
que se afirma muy consistentemente en los 70, a novelar las culturas subalternas o los aspectos más marginales de la cultura popular urbana —o suburbana - que aparece en escritores como Armando Ramírez. Se trata de un escritor que se ocupa de los efectos de la cultura de masas en los sectores populares y de la violencia cotidiana. Lo mismo sucede en Las glorias del Gran Púas (1978) o en Acapulco (1979), ambas de Ricardo Garibay. De esta tendencia narrativa dice Sara Sefchovich:

En La vida no vale nada (1982), Agustín Ramos mantiene sus obsesiones: el difícil juego narrativo y el afán poético con la preocupación por la represión, por el pobre valor de nuestras vidas frente al abuso y al crimen ya institucionales. Esta novela es "una indagación lúcida y eficaz en torno al acontecer nacional". Sus personajes, habitantes de una colonia proletaria del D.F. se involucran con representantes de otros sectores para hacer afforar los abusos, la corrupción, la violencia, la homosexualidad. Ramos es un ejemplo de literatura bien hecha y comprometida. Lo mismo es Armando Ramírez, quien publicó en 1972 Chin el Teporocho, crónica y recreación del barrio de Tepito. Maestro de la técnica, profundamente crítico, retrata a las clases populares sin afán costumbrista, alejado de la cultura con mayúscula, pero profundamente culto, y abierto a los nuevos lenguajes no sólo para decir lo suyo sino para ser leido por gente distinta (el subrayado es mío). El lenguaje del radio y de la fotonovela se unen así a estrategias narrativas que parecen demasiado simples y que se montan sobre el eje que atraviesa la novelística de Ramírez: la violencia. La violencia que es la única verdad de este país. La violencia como robo, como muerte, como poder. Y junto a ella, una carga sexual que en Violación en Polanco (1981) es aterradora, en Noche de Califas (1982) es cachonda, y en Quinceañera (1987) es ridícula (223 y 224$){ }^{7}$

Relacionados con el ambiente burocrático y empresarial destacan Los ritos del confeso (Ángel B. Ezeta 1977) o Río revuelto (Mercedes Manero 1983); y en cuanto a la clase media, menciono las novelas de Luis Zapata De pétalos perennes (1981) y Melodrama(1983). Este autor, que mucho me hace pensar en el escritor argentino Manuel Puig, continuó el tema de la homosexualidad masculina cuyos antecedentes literarios son Después de todo (José Ceballos Maldonado 1969) y El desconocido (René Rodríguez Cetina 1977). En lo que respecta al tema de la homosexualidad femenina, éste se inauguró con Amora (Rosamaría Roffiel 1989) y con Dos mujeres (Sara Levi Calderón 1990).

Hasta aquí, la consolidación artística de ambientes y personajes marginales en los espacios urbanos, de seres marcados socialmente con algún tipo de degradación, antes no tan visibles en la literatura. Asimismo, resaltan algunas de las modalidades de la clase media y la presencia del burócrata y del empresario, sujetos determinantes en las relaciones políticas y económicas de la vida social. Los temas y los procedimientos narrativos revelan también el impacto de la cultura de masas. Nuevos protagonistas: mujeres como Jesusa: soldadera, obrera, lavandera, lumpen, y otras de clase media: trabajadoras, profesionistas independientes, ya solitarias y conflictivas o ya placenteras y plenas. El ambiente burocrático y empresarial muestran personajes emancipados pero desarraigados; homosexuales problematizados o cada vez más legitimados; califas (padrotes) trágicos,

${ }^{7}$ Lo dicho por Sefchovich vale para otras obras como Violeta Perú (Luis Arturo Ramos, 1979); Sobre esta piedra (Carlos Eduardo Turón, 1981), La calle que todos olvidan (Joaquín Bestard, 1982), etcétera. 
boxeadores, etcétera, van sustituyendo en la narrativa de ficción a los campesinos, obreros y pequeños burgueses solitarios y atormentados con su conciencia. En la expresión: léxico y sintaxis violentos, múltiples técnicas de vanguardia, mezcla de géneros: novela, testimonio, crónica, periodismo, ensayo.

\section{la Matanza de Tlatelolco y el "Bildungsroman"}

El otro texto que inicia los setenta, La noche de Tlatelolco, es la magistral crónica o testimonio de historia oral del movimiento estudiantil del 68. Obra literaria, sin duda, gracias a su complejidad estructural, a la organización artística de sus materiales y al cuidadoso trabajo sobre el lenguaje sin deformar el carácter de lo escrito o lo dicho por los autores múltiples del libro. "Elena Poniatowska logró integrar el 68 a la memoria nacional (...) es (...) uno de los mayores triunfos del movimiento estudiantil de ese año; y uno de los logros más importantes de la sociedad civil. La mujer que le tapó la boca al poder" (Blanco 35). Después, Poniatowska seguirá haciendo crónicas, recogiendo testimonios como en Fuerte es el silencio (1980), ;Ay vida, no me mereces! (1985), Nada, nadie: las voces del temblor (1988); seguirá haciendo la otra historia, la de los oprimidos, y como dice Blanco, "inventándola como literatura". En su actividad narrativa de ficción, publica en $1979 \mathrm{De}$ noche vienes, La "Flor de Lis" (1988) y, recientemente, su más ambiciosa y mejor lograda obra junto con La noche de Tlatelolco: la novela Tinisima (1992), en la cual se da la síntesis perfecta de la literatura y la historia.

En La noche de Tlatelolco reconocemos la matriz generadora de la narrativa del 68 que, sin duda alguna, es identificable en el conjunto de la producción de estas dos décadas y que yo llamo narrativa tlatelolca (véase López 1987). ${ }^{8}$ Estas obras, que pueden reconocerse por su referencialidad al 68, en unos casos hacen de los hechos el centro de la narración; en otros elaboran sus consecuencias individuales y colectivas, o lo utilizan como telón de fondo. Mientras más cercanos a los hechos, los narradores trabajan también con formas narrativas no ficcionales como el testimonio, la crónica o la autobiografia (Luis González de Alba en la novela testimonial Los días y los años (1971), María Luisa Mendoza en Con él, conmigo, con nosotros tres (1971), Arturo Azuela en Manifestación de silencios de 1979).

Esta última novela es una de las que mejor recrea el contexto histórico y cultural de la época. Reflexión sobre el mundo intelectual y político que, muy diferente a La mafia de Piazza o Los juegos de Avilés Fabila en los sesenta, muestra el pesimismo, la incertidumbre de la inteligencia y de la juventud mexicanas en ese momento: "la hora de la pesadumbre", le llama Sara Sefchovich a los setenta. De Manifestación... Federico Patán expresa: “Azuela mira al pasado con distancia literaria de por medio, e indaga qué mundo fue aquél del 68 , cuando Tlatelolco se volvió de pronto línea divisoria, un antes y un después de dolorosísima

\footnotetext{
${ }^{8}$ Acerca de la existencia o no de la narrativa del 68 , continúan las opiniones contradictorias, como también las hubo y las hay con respecto a la Onda y, en la actualidad, con respecto a la narrativa femenina. Lo cierto es que los hechos concretos existen y, frente a su evidencia, lo que resulta necesario es la investigación, más que la negación o las opiniones aproximativas, para definir los criterios de caracterización y periodización de la producción literaria desde 1950 en adelante. Trabajo que sistemática y orgánicamente, es el que no existe.
} 
memoria" (74). En este comentario, está contenido lo que a mi juicio une a toda esta producción sobre el 68, en la que se explica, justamente, la condición de parteaguas del hecho político que determina también un parteaguas en la conciencia nacional e histórica $\mathrm{y}$, evidentemente, en lo cultural y específicamente literario. Creo que con respecto a México, el 68 inauguró prematuramente la conciencia estética del posboom en los términos que la define Marcos.

La necesidad de dar testimonio de los acontecimientos fuerza al escritor a recuperar muchos elementos de la estética realista y de otros géneros no ficcionales. La experiencia vivida en la inmediatez de la conciencia individual y colectiva, en el yo que se transforma en nosotros, es el impulso histórico y vital de la narración al margen de la fantasía o la imaginación de una conciencia individual privilegiada. Y, como en la Novela de la Revolución, los escritores recuperan recursos de la tradición e inventan otros para enfrentar, artísticamente, los hechos. En Al cielo por asalto (1979), Agustín Ramos también recrea el contexto histórico y, siendo como es una novela que asume la posición revolucionaria al tiempo que generacional, trasciende por la mediación política la novela de la Onda y es, por lo menos para mí, la obra con la cual culmina y se supera esta corriente que introdujo cambios formales, temáticos y nuevas concepciones en la novela mexicana, y no con Se está haciendo tarde (final en laguna), de Agustín.

La evolución de una conciencia netamente individual y narcisista hacia el desarrollo de una conciencia histórica amplia que se identifica con un nosotros, es lo que tienen de común todas estas novelas que expresan una fractura en la percepción de la realidad y una reorganización de la misma en términos de la revaluación de una pertenencia histórica en lo nacional o latinoamericano. Todo esto resulta muy apreciable en Compadre Lobo (1977) de Gustavo Sainz, novela en la cual a manera de recurso formal, como leit-motif dirigido hacia la conformación del sentido textual, se reitera la autoreflexión sobre un "no saber" individual que se transforma en un "no sabíamos". En dicho texto, igual que en casi todas las obras sobre el 68, incluso en las más subjetivas como La invitación (Juan García Ponce, 1972) o alejadas temporalmente, el movimiento estudiantil y la matanza que desencadenó, operan como hechos traumáticos y sorpresivos que hacen madurara los jóvenes protagonistas. En general, la Matanza de Tlatelolco supuso en la conciencia de la generación de escritores nacidos después de 1940, una especie de prueba o rito de iniciación, un pasaje, incompleto o definitivo según los casos, hacia la madurez y la compresión de la realidad individual articulada a lo social. Un relato breve y paradigmático en este sentido es "Venir al mundo" (Guillermo Samperio, Miedo ambiente, 1977). ${ }^{9}$

\footnotetext{
${ }^{9} \mathrm{El} 68$, como marca de pasaje, opera a manera de horizonte de comprensión en los 70 y en los 80 , por eso sigue reapareciendo en novelas que se identifican como históricas, políticas, generacionales, etcétera. Algo semejante ha sucedido con la Revolución Mexicana que, a setenta años de distancia y a pesar de haberse decretado su muerte simbólica y práctica reaparece en muchas producciones del presente. Ambos hechos históricos y su productividad simbólica, me hacen pensar en que para los escritores nacionales la historia es vivida como un elemento constitutivo y consciente de la mexicanidad que, a pesar de los denuestos, ridiculizaciones y resentimientos, explica la fusión reiterada de ésta y la literatura. Un ejemplo de este profundo lazo de amor-odio con respecto a la historia nacional, es Carlos Fuentes. Algunos textos que a bastante distancia del 68 reflexionan sobre los hechos, o la generación de los 60, o de su condición de marca de pasaje en la conciencia, son: ¿Por
} 
Otras novelas del 68 enfocan más sus aspectos políticos, como Los símbolos transparentes (Gonzalo Martré 1978), o la más alegórica y satírica que es El gran solitario de palacio (René Avilés Fabila 1971). También es importante mencionar La plaza (1972) de Luis Spota, donde el autor cuestiona políticamente al Movimiento del 68.

\section{POLITICA Y "MUERTE MEXICANA" ALREDEDOR DE LA HistoRIA}

Así pues, crónica, testimonio, autobiografía, reflexión política, atípicos bildungsroman alrededor del Movimiento y la matanza estudiantil del 68, nos llevan de la mano hacia otras dos tendencias que surgen en los setenta y ochenta: la novela histórica o historia novelada, y la novela política que desde La sombra del caudillo (Martín Luis Guzmán 1929) no tenía una tan poderosa expresión como en Morir en el golfo (Héctor Aguilar Camín 1986). Violencia, política e historia, el mundo periodístico - tratado por Vicente Leñero en Los periodistas (1978)-, se conjugan también con la nostalgia de los tiempos idos en otra obra de Aguilar Camín: un enorme fresco histórico, político y cultural de la generación que abrió los ojos a la realidad en el 68 y que es La guerra de Galio (1991). Con esta novela terminaría, según mi criterio, la etapa narrativa que estamos estudiando. ${ }^{10}$

En cuanto a la novela política, este fue un subgénero muy trabajado por Luis Spota, escritor poco considerado en la "alta" cultura, pero de quien habrá que hacer un estudio minucioso para entender el mosaico de la narrativa mexicana contemporánea. Spota escribió una tetralogía política cuyos títulos son: Retrato hablado (1975), Palabras mayores (1975), Sobre la marcha (1976), y El primer día (1977). A estas obras le siguió el ciclo de La costumbre del poder, que consta de seis títulos.

En los setenta, la preocupación política es muy obvia - gracias también a la apertura democrática-, y Spota atendió especialmente a esta preocupación en lo literario. Sin embargo, no sólo en la ficción se hizo presente el tema, sino también en la gran cantidad de obra ensayística donde se trató de comprendery desmitificar el orden de la política nacional. Entre ellas, destaca especialmente El estilo personal de gobernar, de Daniel Cosío Villegas, porque así como el movimiento estudiantil del 68 fracturó en los hechos la estructura monolítica del poder, Cosío Villegas arremete contra su más consistente manifestación: el presidencialismo, desacralizando esta casi mítica institución de la cultura y la política mexicanas. ${ }^{11}$

qué no dijiste todo? (Salvador Castañeda 1980); Muertes de Aurora (Gerardo de la Torre 1980); Las batallas del desierto (José Emilio Pacheco 1981); Si muero lejos de tí (Jorge Aguilar Mora 1982); Que la carne es hierba (Marcos A. Campos 1982); Criatura de un dia (Juan Tovar 1983); Pánico o peligro y Antonia (María Luisa Puga 1983 y 1989); A la salud de la serpiente (Gustavo Sainz). Otro más reciente es un libro de apuntes y memorias: 68 (Paco Ignacio Taibo II 1991).

${ }^{10}$ Otros autores mucho más jóvenes han iniciado un nuevo momento de la narrativa del posboom a partir de aspectos más íntimos y una prosa más transparente: David Martín del Campo (1952) en Isla de Lobos, Dama de noche o Alas de Angel; Juan Villoro en La noche navegable, Albercas, pero en especial en El disparo de Argón, una obra que inicia a manera de novela negra, la década del 90 y quizás, también, una nueva etapa de la narrativa mexicana.

"Asimismo, aparecieron obras testimoniales y autobiográficas de figuras políticas como periodistas, gobernadores, generales, quienes contaron sus experiencias. Vale la pena recordar que en los setenta, 
Del trauma del 68 y de la supuesta apertura democrática, surgió un nuevo impulso para entender la historia y la política mexicanas. Y en la literatura, además de la narrativa del 68, comenzó a apreciarse la emergencia de una preocupación histórica que, con diversos procedimientos, exploró los acontecimientos más lejanos para explicar el presente o, simplemente, para organizar la experiencia inmediata y mediata. Se trata en la mayoría de los casos, más que de novela histórica al estilo tradicional, de un trabajo literario vanguardista y muchas veces muy subjetivo sobre algunos episodios o épocas específicas. Lo importante es que a partir de entonces lo individual se vuelve a pensar histórica y colectivamente.

Existe, además, una tendencia festiva, irreverente, que parodia a la historia. Uno de sus iniciadores es Jorge Ibargüengoitia (1928-1983) con novelas como Los relámpagos de Agosto (1964) o Los pasos de López (1981). En el horizonte de la Novela de la Revolución, muchos años antes, José Rubén Romero (1890-1952) iniciaría esta especie de picaresca histórica con La vida inútil de Pito Pérez (1938).

Se trata, pues, de una visión humorística, muchas veces grotesca, de la historia y de la política en distintos períodos. Está presente en El Chanfalla (Martré 1979) y, articulada también a la parodia policíaca, se desarrolla en una excelente novela de la que poco se ha dicho: Una piñata llena de memoria (1984) de Daniel Leyva. Dicho texto abunda en lo "grotesco", recurso muy importante en la novela mexicana y poco analizado. Igualmente sucede en Asalto al cielo de Agustín Ramos; en las tres novelas de Fernando del Paso; en la obra de una mujer excepcional que lo manejó con especial virtuosismo (aunque tampoco se ha subrayado bastante este aspecto): Rosario Castellanos; y, desde luego, en Carlos Fuentes quien lo utilizó con énfasis en la casi delirante obra Cristobal Nonato (1987). ${ }^{12}$

Si la Onda fue producto directo de los jóvenes escritores en los mediados de los sesenta y principio de los setenta; y si a partir del 68 se hizo sentir la presencia de Revueltas como modelo político y literario, no creo menos cierto que también el del Paso de Palinuro de México (1977) y su memorable "muerte grotesca", influyó reactualizando la visión de la "muerte mexicana" concebida, magistralmente, por el grabador José Guadalupe Posada (1851-1913). Este artista plástico ha tenido una influencia determinante en la imaginación simbólica de la cultura mexicana, y en esa modalidad irónicamente festiva en torno a la

también dos mujeres contaron sus experiencias cercanas a los centros del poder político o económico; ellas fueron Irma Serrano con el libro A calzón amarrado; e Irma Salinas, quien reveló en el libro Nuestro grupo los procedimientos turbios del poderoso Grupo de Monterrey.

${ }^{12}$ En un trabajo sobre Rosario Castellanos, analizo la visión grotesca que estructura el cuento "Cabecita blanca". Castellanos ironiza sobre el absurdo grotesco de situaciones clasemedieras mexicanas en Álbum de familia (1971) y, particularmente, en su obra póstuma Eleternofemenino. En toda su producción, según mi criterio, fue dándose un desarrollo progresivo de la visión grotesca que tiene una tradición hispánica desde las danzas de la muerte hasta, en México, las calaveras de Posada o las calaveras de azúcar de las festividades del Día de Muertos. Grotesca también es la imagen de la realidad en los escritores de la Onda. Y la de del Paso en Palinuro de México (1977) e, incluso, en algunos aspectos de José Trigo (1966) y Noticias del Imperio (1987). Y así como la Matanza de Tlatelolco instaló una vez más la "extrañeza" típica de lo grotesco, los escritores la incorporaron en sus obras en 1970 y 1980 - como antes lo hizo Castellanos - para tomar una posición crítica frente al poder (véase López "La vida es un espejismo ..., 127 a 157). 
historia. Lo grotesco, sin duda relacionado con la percepción contradictoria y humorística de la realidad, tiene también una connotación patética y muchas veces trágica. Esta visión y su técnica correspondiente, es una de las características dominantes de la narrativa mexicana que comenzó a emerger tímidamente a finales de los cincuenta, fue tomando brío en los sesenta, tuvo un buen punto de visibilidad en la producción "ondera", y continuó filtrándose consistentemente en el tejido narrativo de la producción literaria de los 70 y los 80.

Quizá, la manera innovadora de cronicar de Carlos Monsiváis, cuya obra nadie dejaría de tomar en cuenta en el período literario que nos ocupa, ni tampoco dejaría de relacionar con la tradición irónica y también festiva del cronista de la Ciudad de México por excelencia, Salvador Novo, forman parte de una tendencia cultural mexicana que constituye una forma de tradición mediante la cual se hace burla de las rígidas e inamovibles jerarquías culturales, incorporando la fuerza genérica de lo popular y cotidiano. Es curioso, porque siempre se ha hablado de la visión trágica y solemne del mexicano, pero mucha de su producción cultural la niega. ${ }^{13}$

\section{LA CRÓNICA: GÉNERO “CLÁSICO" CONTEMPORÁNEO}

Cuestión muy notable en estas décadas es la presencia de la crónica. Entre las obras de Carlos Monsiváis se cuentan Días de guardar (1970), Amor perdido (1977), A ustedes les consta (1980) y otras. Esta última es una antología de la crónica mexicana desde el siglo XIX, lectura imprescindible para la investigación. En la actualidad se están haciendo tesis doctorales que reflexionan sobre este género que, seguramente, será considerado un clásico del período en el futuro. Quizás sea en la crónica donde se han estado dando, consistentemente, las mejores páginas de la historia literaria de estas décadas. Domínguez dice lo siguiente a propósito de Monsiváis:

Carlos Monsiváis (...) hombre público, cronista de la vida ciudadana y patricio cívico de los descamisados. Escritor indispensable para comprender los últimos veinticinco años de la cultura mexicana. (...) Inexplicable sin Novo y sin el nuevo periodismo anglosajón, para Monsivaís el país entero es una ficción infinita. Días de guardar (1970), en un momento de zozobra política, reveló a muchos la posibilidad de que un escritor mexicano volviera a ser, dada la lamentable conducta servil o indiferente que caracterizó la actitud de Reyes, Vasconcelos, Guzmán y Novo ante el poder, una conciencia crítica ( 68 y 69).

Monsiváis es una conciencia crítica, sin duda, lúcida y mordaz que ha impuesto un estilo muy especial y divertido para decir y pensar el país. Ha influido enormemente en las nuevas generaciones y su forma de narrar transforma a la crónica si no en novela, sí en relato literario. En el campo intelectual de la cultura mexicana contemporánea, Monsiváis es un

\footnotetext{
${ }^{13}$ Existen muchas ideas erróneas sobre la idiosincrasia mexicana. Se trata de un pueblo "viejo" y con experiencia, que ha organizado una perspectiva de la historia, intensa y vital, consciente de la precariedad de la condición humana y de las múltiples intervenciones del azar. Por otro lado, sus intelectuales y escritores han pensado profundamente sobre la conformación de la trayectoria nacional. Un extenso acervo bibliográfico constituye su muy consolidada tradición.
} 
maestro que dicta cátedra de imaginación histórica, lingüística y literaria. El narrador cronista demuestra, como lo ha hecho del Paso en Noticias del imperio (1987), que la historia también se engendra en los acontecimientos cotidianos y en la imaginación de los hombres. Así, la imaginación compite con la realidad o es, parte misma de ella. Entonces, ¿dónde están los límites entre la ficción y la realidad que invoca el discurso histórico? Esta es una pregunta claramente planteada y también bastante respondida en buena parte de la literatura mexicana contemporánea. Si la reconstrucción histórica pasa ineludiblemente por el discurso y por la imaginación, la historia es pariente de la literatura y, ésta, es su legítima colaboradora.

Elena Poniatowska, excelente cronista, es capaz de mostrar los costados absurdos y grotescos de la realidad con ironía y un cierto humor. Ella ha contribuido en algunas obras a esta representación cotidiana de México y sus acontecimientos visibles y menos visibles. Nada, nadie (1988), es un texto donde se recogen los hechos y los testimonios sobre el temblor de 1985. Este acontecimiento también tiene su relatora en Cristina Pacheco (Zona de desastre, 1985). ${ }^{14}$ Y la más ambiciosa de las novelas de José Agustín, Cerca del fuego (1986), literaturiza la catástrofe y la destrucción de la ciudad, parodiando autores, obras y citas de la cultura occidental en pleno. Otra novela interesante sobre el sismo, poco distribuida, es Viaje (Rafael Rodríguez Castañeda 1991).

A propósito de Cristina Pacheco, ella es una exponente reconocida del periodismo sobre la Ciudad de México, sus habitantes más desposeidos y los migrantes que llegan todos los días desde los Estados buscando mejores condiciones de vida. Ha publicado recopilaciones que exhiben un panorama de estos espacios urbanos populares y un repertorio de historias estrujantes. Algunos títulos son Para vivir aqui (1983), Sopita de fideo (1984), La última noche del "tigre" (1987).

José Joaquín Blanco, imprescindible sin duda, es novelistay cronista. En 1979 publicó La vida es larga y además no importa, en la cual tematiza la cotidianidad de la clase media. Posteriormente, Las púberes canéforas y Calles como incendios, de las cuales Sefchovich dice que a partir de lo individual, recrea la ciudad y sus convenciones con lucidezy con rabia. Ha publicado además Crónica de la poesía mexicana y las recopilaciones de crónicas urbanas y literarias La paja en el ojo y Retratos con paisaje. Muy importante es, asimismo, la contribución de Jorge Aguilar Mora con el ensayo, crónica, novela y autobiografía que es Una muerte sencilla, justa, eterna (1990). José Emilio Pacheco, Aguilar Camín, Leñero y Ricardo Garibay también han hecho excelentes crónicas y periodismo literario.

\section{USO NARRATIVO DE LA NOTA ROJA}

Mención aparte merece la crónica policial. En A ustedes les consta Monsiváis estima que es en ella donde ciertos cronistas denuncian abusos de poder y muchos acontecimientos

\footnotetext{
${ }^{14} \mathrm{El}$ sismo, para muchos, fue otra especie de 68, en este caso natural, que dejó aflorar nuevamente el escándalo social y político y la corrupción, aunque también mostró la fuerza popular de la ciudad. La lucha por la reconstrucción de viviendas ha resultado una forma alternativa de hacer política en los barrios de Tepito, Guerrero y Morelos. El centro de la ciudad y sus habitantes de procedencia más popular, se han organizado y constituyen hoy una fuerza política. En lo artístico, una muestra de la representatividad actual de estos barrios es el grupo Tepito Acá.
} 
ocultos. Destaca, entre ellos, a Ramón Márquez (véase $A$ ustedes les consta, 362). Con respecto a lo criminal y policíaco en Asesinato (1985), Vicente Leñero relata la historia del crimen del viejo político Gilberto Flores Muñoz y su esposa, la escritora Asunción Izquierdo. Con rigor documental analiza el hecho y busca la verdad, denunciando sus entretelones políticos y policíacos. Algunos la tratan como novela reportaje, pero es un caso de difícil clasificación. Antes, Leñero indagó lo policial en su famosa obra de teatroy novela Los albañiles (1964) y en otras más. A veces también lo policial se asocia, igual que lo político, a la historia.

La novela policial es un subgénero relativamente reciente, y goza de buena salud en México. Su novela ya clásica es El complot mongol (1969) de Rafael Bernal. En muchas obras del período hay intrigas policíacas, pero en cuanto a la consideración del subgénero en su modalidad más puntual, los autores que la han trabajado son Paco Ignacio Taibo II y Eugenio Aguirre en Segunda persona (1985) (paródica) y El rumor que llegó del mar (1986). Destacan también un grupo de mujeres: María Elvira Bermúdez — fallecida recientemente-, Malú Huacuja y Ana María Maqueo. De esta tendencia dice Puga:

Hay un auge de novela policíaca porque el género permite aproximarse a la temática social desde un nuevo ángulo, menos moralizante y más revelador tal vez (Teichmann 143).

\section{Provincia y COSMOPOLITISMO}

Es evidente que la novela de estos años muestra una gran diversidad en la representación de esferas y personajes sociales, ambientes, épocas; en lo genérico también se confunden entre sí los grandes géneros y los subgéneros. Asimismo pasa en lo temático. Existe un conjunto de novelas que abordan la provincia y lo rural, y otro en que desde un espacio internacional los protagonistas mexicanos reflexionan acerca de la significación de México así como de su historia, en relación con ellos mismos.

En los 70 también se vuelve a la provincia y a lo rural. Pero esta recuperación de lo regional tiene razones diferentes a los del pasado. La provincia ahora también se ha urbanizado, y tiene además de los antiguos conflictos, otros nuevos. Por otra parte, la expansión económica y el trabajo cultural realizado en los Estados por estos mismos años, permite que algunos escritores permanezcan en su lugar de origen. Este regreso a la región se observa en El aguacero (Luis R. Moya 1977), La canción de las mulas muertas y El sol que estás mirando (Jesús Gardea 1979 y 1981), Pasos de sangre (Eugenio Aguirre 1989), Hombres de temporal (Herminio Martínez 1989), Nos imputaron la muerte del perro de enfrente (Alejandro Hernández 1989).

Otros escritores, cosmopolitas, indagan a México desde el extranjero para recuperar, la mayoría de las veces, una identidad personal y nacional más consciente y positiva. Entre ellos, Manjarrez (1945) con Lapsus (1971), Aguilar Mora, con Cadáver lleno de mundo (1971), y Si muero lejos de tí(1971), Daniel Leyva (con sus dos novelas), María Luisa Puga con Las posibilidades del odio, y Antonia. Cosmopolitas son, sin duda, Salvador Elizondo, Carlos Fuentes, Sergio Pitol, Octavio Paz, quienes han vivido bastante tiempo en Europa o en Estados Unidos, como todos los mencionados. También José Agustín hace una revaloración de la cultura mexicana y del país en general en Ciudades desiertas (1983), en contraste con la sociedad norteamericana. Leyva en $\& A B C D E r i o . . . ?$, toca un tema poco 
usual, el de los exiliados políticos latinoamericanos en el París de los setenta. Puga lo hace en Antonia, pero desde Londres.

Sin embargo este cosmopolitismo es diferente al de los 60 . Los autores manejan una perspectiva internacional (mundializada) mediante la cual reflexionan sobre el país.

HISTORIA Y VIDA COTIDIANA: NACIÓN, CIUDAD, BARRIOS Y FAMILIA

En este período se observa que la preocupación histórica ha ido en aumento, y que ésta se asocia a la vida cotidiana y se integra a la conciencia individual de los narradores y de los personajes. Este interés no excluye tampoco el sentimiento nostálgico. ${ }^{15}$ La asunción de la vida cotidiana en el marco de lo histórico es, justamente, el contexto de la reflexión existencial subjetiva. La revaloración de la existencia cotidiana ha sustituido, tal vez, a las visiones universales de los grandes sistemas de pensamiento. Y este desplazamiento podría explicar el interés por capturar en oposición a los grandes espacios, los rincones, los barrios, las casas, los pequeños espacios, en contraste con la gran ciudad o los ambientes indiferenciados. Y todos sabemos que la imaginación se construye en el horizonte posible de la infancia dentro de la familia y de esos pequeños espacios que el niño o el adolescente reconocen. Por eso también la presencia de la nostalgia.

Dicha nostalgia se aprecia en la tendencia a manejar artísticamente materiales autobiográficos que abundan en lo cotidiano. Me parece necesario señalar, para explicar algunos aspectos de esta nostalgia, que el área urbana de la Ciudad de México era, en 1970, de $650 \mathrm{Kms}$. cuadrados, aproximadamente; y que, en 1992, es de más o menos 1,300. Esto muestra cómo en veinte años la ciudad fue volviéndose inabarcable, extraña (extranjera), para sus habitantes, extrañeza perfectamente literaturizada en este período, junto con sus consecuencias intimas de desarraigo y, en lo exterior, de nuevos conflictos sociales. Asimismo, en muchas obras que focalizan el barrio y los espacios pequeños, está presente una reacción alternativa mediante la cual se intenta enfrentar esta pérdida del sentido de pertenencia con una voluntad - aunque sea simbólica e imaginaria- de ganar el arraigo. Creo que esto explica, sólo en parte desde luego, esa insistente recreación de ambientes barriales, de historias familiares, de ciertas épocas pasadas de la ciudad, así como el énfasis general en la historia.

Algunos ejemplos de esto último, a reserva de precisiones mayores mediante una investigación de carácter riguroso, son Las batallas en el desierto (José Emilio Pacheco 1981), donde se reconstruye el ambiente de la Ciudad de México durante la década de 1940

\footnotetext{
${ }^{15} \mathrm{John}$ Brushwood hace referencia a este fenómeno en su libro La novela mexicana (1967-1982), de 1985, en el cual elabora un valioso intento de ordenación e interpretación de la narrativa de este período y delinea ciertos rasgos que han permitido iniciar la reflexión con respecto a estas décadas. Entre los rasgos significativos marca la autoconciencia del proceso de creación, la presencia espectral de Tlatelolco, la identidad inestable, la nostalgia que matiza también a la tendencia narrativa histórica, la demanda de participación del lector y, por último, la literaturización de la ciudad. En este aspecto, consigna que más que enfocar la ciudad como totalidad, los escritores tienden a novelar los barrios, las colonias, pequeñas áreas diferenciadas. A estos espacios Brushwood los caracteriza como "mi tierra", interpretación reducida de la ciudad que, según él, comienza en las novelas de la Onda (17-33).
} 
y se registra históricamente la tragedia del 68; Parejas (Jaime del Palacio 1981), novela en clave en la que se recrea los cincuenta por medio de historias de parejas. El perro de la escribana (María Luisa Mendoza 1982); Pánico o peligro (María Luisa Puga 1983), donde se reconstruye el ambiente de los 60 y de $\operatorname{los} 70$ en un pequeño perímetro de la ciudad en el cual algunos tramos de la calle de Insurgentes son básicos; Arráncame la vida (Ángeles Mastretta) aborda el ambiente de los 30 a los 40 en el Estado de Puebla y en la Capital; Una piñata llena de memoria (Daniel Leyva 1984), en la cual se narra la historia de la Ciudad de México desde 1879 a 1960; Pasaban en silencio nuestros dioses (Héctor Manjarrez 1987), novela sobre el sur del D.F. y del "sueño" de la generación del 60.

Otras en las cuales se aprecia un mayor énfasis histórico son: Apenas la medianoche (Héctor Morales 1973), en torno a los treinta y sesenta; El tamaño del infierno y Un tal José Salomé (Arturo Azuela 1973 y 1975); Un redoble muy largo (Manuel Echeverría 1974), texto en el que se elabora el período que va desde el porfiriato hasta la presidencia de Luis Echeverría en los setenta. La insólita historia de la Santa de Cabora (Brianda Domecq 1990), donde se recrea a partir de la reconstrucción de la historia personal de Teresita Urrea, el porfiriato a finales del XIX y principios del XX.

Más definitivamente históricas son, Gonzalo Guerrero (Eugenio Aguirre 1980), Ascención Tun (Silvia Molina 1981); en muchos sentidos José Trigo y obviamente, Noticias del imperio (Fernando del Paso 1966 y 1987). El caso de Terra Nostra (Carlos Fuentes 1975), es muy particular, pero revela evidentemente esta preocupación histórica aunque en un período mayor y en el contexto Europa-América. Ignacio Solares evoluciona a finales del 80 hacia la novela histórica. Prueba de esto es Madero el otro (1989) y La noche de Ángeles (1991). Un texto a caballo entre lo místico y lo histórico - o farsa antihistórica como la califica Domínguez - es Criatura de un dia (Juan Tovar 1983), de la cual el mismo crítico opina que es una alegoría de la generación del 68 . En este terreno existen novelas con afán totalizador que representan e interpretan peíiodos históricos muy amplios, o menos pretenciosas que sólo toman períodos cortos y definidos.

\section{CRISIS DEL GÉNERO NOVELA Y CRISIS DE LA HISTORIA}

Todas las obras o casi todas las que he mencionado están realizadas con base en estrategias narrativas vanguardistas bastante complejas. Asimismo, muchas veces resulta difícil la clasificación genérica o subgenérica (histórica, política, familiar, generacional, etc.). Un ejemplo que es difícil de entender como novela, no obstante que así la designa su autor, es México negro (Francisco Martín Moreno 1986). Esta obra aparece acompañada de notas eruditas e incluso de bibliografia especializada. Se dice de ella que es una novela política en la cual se recrean los primeros cuarenta años del siglo XX y que es una especie de saga del petróleo, recurso en torno al cual se interpreta la época histórica y políticamente. México negro es un caso extremo de la ruptura de géneros y de la confusión de los mismos que caracteriza al período. Obras experimentales que desafían al género mismo son las de Fernando del Paso y algunas de Carlos Fuentes. Igualmente, las dos novelas de Leyva y Cadáver lleno de mundo (1971), Si muero lejos de tíy, aún más, Una muerte sencilla, justa, eterna (1990), la tres de Jorge Aguilar Mora (1945).

Muchos textos desbordan el género. En este sentido es que se puede hablar hoy de la crisis de la novela: su mutación e hibridación, que coincide con la crisis del concepto de 
verdad en otros espacios del conocimiento, en particular con relación a la historia. La pérdida de veridicción de los grandes sistemas de pensamiento de la modernidad occidental, relativizan y fragmentan la comprensión de la realidad provocando desaliento y escepticismo. Así, nada tiene de raro que en la novela esto se muestre también. La despreocupación por la verosimilitud literaria, en muchos casos, y la ruptura de las convenciones que antes nos orientaban, responden a la desfamiliarización de nuestro mundo, a su desterritorialización. El aparato tecnológico cambia el rostro de lo que creíamos realidad y ésta se hace extraña. Por eso tal vez la visión y la técnica de lo grotesco en buena parte de esta narrativa.

Por otro lado, es muy frecuente también que la historia se entienda como equivalente a la política como en Muerte en el golfo, y sin excluir la "nostalgia", en La guerra de Galio, ambas de Aguilar Camín. Aunque esta novela, en clave, ya no pertenece a los 80 , sin embargo, me parece ilustrativa de la problemática de estas dos décadas. A propósito de su presentación en julio de 1991, el comentarista dijo lo siguiente:
¿De qué se trata?, preguntó Hugo Hiriart. Se ha dicho que es una novela política, pero eso no es decir gran cosa. (...) "La política no es su tema; el mito, la leyenda que van construyendo sus páginas no tratan de eso. Mi opinión es que el asunto que unifica la novela es, digamos humano, existencial".
José Joaquín Blanco observó que se relata el esfuerzo de un narrador. "Una novela que trata de la escritura de una novela es uno de los recursos más agraciados en la historia de la literatura. (...)
Carlos Monsiváis consideró que para los lectores mexicanos, La guerra de Galio es la brillante recreación del mundo desesperanzado de la generación del 68 , marcado por el aborrecimiento de la "política", por el miedo gozoso a la asimilación (...).
Hizo notar que en esta novela lo único equivalente en importancia a las ideas es la genitalidad, el amor como obsesión. Pero en el curso de sus páginas las ideas ocupan el primer plano (Molina 36).

Creo que lo anterior es una síntesis del período: la novela política, la novela de la generación del 68, la novela histórica, la novela de nostalgia, la novela de la ciudad, la novela de metaficción, la novela existencial, la novela erótica, en una misma obra. ¿De qué se trata? La respuesta espera un trabajo sistemático de investigación sobre el período.

\section{CONCLUSIONES SIN CONCLUSIÓN}

Mucho queda por decir con respecto al panorama todavía confuso y abigarrado que nos presenta la narrativa desde 1970 en adelante. Es importante precisar la composición de los grupos literarios que funcionan alrededor de las revistas Vuelta, Nexos, los suplementos culturales Unomásuno, la Jornada semanal y otros. También es muy considerable el cambio que se ha operado en el país a partir de la gestión del presidente Salinas, a finales de los 80 , que incluye además una reestructuración de las políticas culturales. ${ }^{16}$ No hemos

\footnotetext{
${ }^{16}$ Una nueva institución ha desplazado al Instituto Nacional de Bellas Artes y su Departamento de Literatura que en los 70 promovió los talleres literarios y fundó casas de la cultura en toda la nación; fomalizó programas de publicación y apertura de revistas, entre las cuales se editó por los setenta Tierra adentro, dirigida por el escritor ecuatoriano Miguel Donoso Pareja, encargado también de la
} 
abordado tampoco las condiciones en las que se ha venido desarrollando la crítica literaria periodística y académica. Ni la circulación de revistas literarias. Tampoco hemos aislado, dentro de la narrativa, la producción cuentística que tiene en la Universidad Autónoma de Tlaxcala su principal centro de investigación. Todo esto faltaría para precisar mejor la configuración del campo literario en estas décadas. Por lo pronto, trataré de apretar algunos de los muchos hilos sueltos que hemos venido manejando.

Primero. El gran problema que nos presenta la enorme diversidad de esta narrativa, es la ausencia de criterios para organizarla y explicarla en lo formal (procedimientos expresivos) y en lo conceptual y temático. Asimismo, ¿desde dónde asumir la perspectiva, considerando, en lo particular, la tradición mexicana y, en lo general, la latinoamericana? Por ejemplo, un corte temático mostraría que una misma novela ocupa varias clasificaciones; un corte por género, sub-género o procedimientos narrativos, mostraría también que un mismo autor los aborda y los mezcla todos a lo largo de su trayectoria literaria, como es el caso de Eugenio Aguirre. El problema, pues, consiste en crear y definir criterios para recortar esta producción y periodizarla en lo posible.

Segundo. Es necesario asumir un nuevo elemento en el campo literario: el mercado, forma inestable y sui generis, extraño y enemigo de la institución literaria en su versión tradicional y canónica, pero que la "interviene" y transforma. Este elemento "extraño" explica bastante la crisis de criterios para evaluar la manifestación literaria, lo que forma parte también de la crisis del hegemonismo cultural de Occidente. En este sentido, mucho han tenido que ver, además, las realidades diversas que presentan las culturas del Tercer Mundo o las subordinadas en general. Estamos ante la necesidad de una redefinición de lo cultural y de una revaluación crítica global en el campo mayor de las humanidades y en el más restringido de la literatura. Por lo pronto, han estallado los límites entre las llamadas culturas alta, media y baja debido a la intervención creciente del mercado, los desarrollos tecnológicos, la transformación de las relaciones sociales y políticas, la ya evidente mundialización de la cultura, planteándonos la urgencia de una visión crítica global que asuma todo esto; y una redefinición del canon y del currículo docente en el seno de la institución literaria. En ausencia de una perspectiva actualizada y de criterios firmes de valor para interpretar la reciente producción, se presenta también una crisis de legitimidad de la misma en el contexto más amplio de una crisis de las humanidades en general.

Tercero. En cuanto a la promoción — también mercantilización- de la literatura, nunca antes existió en México la cantidad de publicaciones, de conferencias, de presentaciones y ferias del libro, como desde los finales de 1970 en adelante. La literatura, sin duda, tiene un valor de cambio y sus manifestaciones se han convertido no sólo en mercancías concretas, sino también en espectáculos y eventos sociales, lo cual es bastante difícil de valorar actualmente. Asimismo, aunque el productor cuestiona todo esto -muchas novelas se burlan de la "erudición" y del campo intelectual - no deja de estar atrapado en el tejido cosificante del mercado.

fundación y dirección de muchos talleres. En éstos, colaboraron bastantes escritores latinoamericanos exiliados por entonces. Hoy, aparece como máximo responsable de la promoción literaria en el país el Consejo Nacional para la Cultura y las Artes que, mediante su Fondo Editorial Tierra Adentro, publica a los más jóvenes escritores. 
Cuarto. Han surgido nuevos sujetos sociales como productores y consumidores literarios. Lamanifestación del "joven", en este sentido, explica a la Onda: cosa perfectamente lógica, además, en un país que tenía y sigue teniendo una enorme población juvenil. Lo mismo vale para esa especie de novedad que es el "intelectual" que prolifera hoy dentro de las culturas subordinadas. En ellas, también existe un gran número de lectores que se reconoce, por ejemplo, en las novelas de Armando Ramírez y muchas otras. Igualmente en el caso de la supuesta literatura "light" que escriben las mujeres en los 80; o en la literatura "gay" desde los setenta. La transformación de una sociedad tradicional en otra consumista $y$ "moderna" -aunque sea de una manera irregular porque siguen presentes las estructuras premodernas - plantea nuevas problemáticas sociales de las que da cuenta la narrativa mediante la diversidad de representación de sus universos. Si todo esto implica una "democratización" o no; o la presencia más fuerte de una sociedad civil; o si puede o no ser explicado por la estética posmodernay por la del posboom en el terreno de lo latinoamericano, son asuntos que rebasan las características de este trabajo, pero queden apuntados como problemas.

Quinto. En la realización formal de la narrativa, resulta evidente la diversidad de procedimientos anunciados por la estética vanguardista y su interpretación dentro del boom. Lo más importante para mí, en lo cualitativo, es que el escritor mexicano y latinoamericano tiene hoy como marco de referencia su propia tradición literaria. La estética de lo real maravilloso y del neobarroco son algunos aspectos de la misma. En el horizonte más lejano, la tendencia realista - casi naturalismo-de la literatura latinoamericana, ha sido recuperada y reelaborada en el marco de las nuevas corrientes estéticas. En este sentido, me parece explicable el apogeo de la visión y de los recursos técnicos de lo grotesco y del humor negro. La violencia en los procedimientos narrativos, en el uso de registros lexicales definitivamente obscenos, las rupturas sintácticas extremas, los juegos de lenguaje de franca intención desconstructiva, a veces hacen irreconocible la tradición que, sin embargo, he tratado de marcar en algunas partes de este trabajo. La visión negra y humorística, grotesca y fársica, carnavalesca, tiene carta de naturalización en el presente período asociada al manejo de la violencia individual y social, y de la posición crítica frente al poder y a la corrupción. De esto no se salvan tampoco las relaciones familiares ni las de pareja. Los vínculos amorosos y los roles sociales y sexuales han perdido, también, los conceptos y los valores básicos tradicionales para ser pensados y vividos.

Sexto. En la conformación psicológica de los personajes y su relación con el mundo, el hecho fundamental es que existe un cambio en la manera de percibir el tiempo y el espacio, así como sus conceptos, que produce confusión. Esto tiene que ver, seguramente, con lo que Brushwood denomina "identidad inestable" tanto en lo personal como en cuanto a la realidad exterior misma. Sin duda, México ingresa a una nueva etapa histórica sin una comprensión global de este proceso y de su destino. Sin embargo, la "nueva" historia no ha saldado sus deudas con las anteriores. El extrañamiento de la realidad se relaciona con esta insistente visión grotesca que aparece en la novelística; pero también con la necesidad de cronicar acontecimientos y vida cotidiana, así como con la de reflexionar sobre la historia nacional inmediata y mediata, y la personal. Se trata de un intento de reorientación en un país que, aceleradamente, se va haciendo extranjero a los ojos de las generaciones nacidas entre los 40 y los 60 . Actualmente, un nuevo golpe de "modernización" transforma la fisonomía de la ciudad de México con ejes viales y distorsiona la percepción del espacio. 
Por todos estos "golpes", Blanco expresa en 1982 que se ha iniciado una nueva cultura mexicana, unida al destino de la civilización occidental, impredecible.

Séptimo. La percepción de la realidad en sus aspectos existenciales e ideológicos, plantea una fragmentación de las visiones de mundo" convencionales. Relacionado con esto, aparece la vacilación en torno al concepto tradicional de las clases sociales y de sus protagonistas. La pérdida de referencias sobre la organización de la sociedad exagera la imagen del estado como fuente de poder, y pierde de vista, relativamente, el de ciertos agentes sociales, así como lo económico y lo internacional en términos de mercado. Este poder, que dispersa y homogeniza a la sociedad civil por medio del consumo y la va transformando en masa, está representado en muchas novelas como manipulación en diversos grados, pero de manera confusa. Sin embargo, para Fuentes en Cristobal ... y Leyva, sí está muy enfatizado. Pareciera, desde la visión dominante de esta narrativa, que la nación todavía se vive como encerrada en sí misma, al margen de los sucesos y determinaciones internacionales. Sin embargo, en los dos grandes novelistas de los setenta y ochenta, Carlos Fuentes y el del Paso de Noticias..., esto ya no es así. En suma, los efectos del poder y su manipulación se describen, pero su distribución y sus fuentes no resultan muy claras.

Octavo. La historia con mayúscula y la pequeña historia se enlazan en una dialéctica de lo individual y lo social plenamente asumida. Por eso aparece en ocasiones la nostalgia. Por otra parte, sin duda la novela histórica, con sus variantes, es una de las tendencias más importantes del período. Por lo dicho en el punto sexto, quizás se explica porque expira una época que es necesario contar, a la manera metafórica del cisne que canta cuando va a morir. La Historia, asimismo, también se equipara con la política, lo económico y lo policíaco, abundando en lo que sería su corriente interpretativa.

Noveno. El análisis sistemático de este periodo espera su oportunidad de investigación en el país. Pero para comprenderlo mejor, sigue pendiente la elaboración actualizada de una Historia de la Literatura Mexicana, proyecto que inexplicablemente no han podido realizar aun los centros con capacidad para ello.

FinaL

En el epígrafe utilizado en este trabajo, Fuentes habla de que la sociedad somos muchos y ya no puede existir un lenguaje hegemónico. Y así se aprecia en este período. En cuanto al proceso histórico de México, en el final de laúltima novela de Aguilar Camín un personaje resume lo escrito por Galio:

Galio Bermúdez escribió el libro que le había prometido a Vigil. Lo tituló La coerción ilustrada. (...) La idea fundamental de La coerción ilustrada era que toda la historia mexicana podía leerse como una lucha de élites modernizantes contra sociedades tradicionalistas, como una permanente coerción civilizadora que bajaba de cúpulas impacientes y despóticas hacia bases inmemoriales y recalcitrantes (587).

$\mathrm{Y}$, asimismo, en cuanto al desarrollo de la novela en este periodo, María Luisa Puga estima que ésta ha dejado de ser urbana para ser de la sociedad civil que se encuentra en la maraña de las ciudades grandes y pequeñas (31). Coincide así con la idea expresada por 
Fuentes y también con Blanco cuando este crítico señala que la literatura de estas tres últimas décadas debe pensarse como el principio de una nueva cultura mexicana en los términos de una cultura civil. En cuanto a Blanco, desde una perspectiva literaria, coincide con lo dicho por Galio Bermúdez en la medida en que declara que la literatura mexicana, por lo menos en la segunda mitad del siglo XX, se nutre del asunto de la brusca y forzada modernización del país. Es evidente, pues, que los escritores mexicanos de estas dos décadas dan cuenta de este proceso.

Una de sus fases aceleradas comenzó a finales de los 40 , y fue perdiendo algo de su velocidad, sin cambiar de dirección, a lo largo de los 70. En lo literario, por el momento, todo parece indicar que esa fase se cierra en esta dos décadas con La guerra de Galio, de Héctor Aguilar Camín (1946); y que ha comenzado una nueva etapa de la literatura mexicana a partir de la mitad de los ochenta con escritores más jóvenes, entre ellos Juan Villoro, que coincide con otra fase aceleradísima de modernización nacional.

Sin embargo, estando de acuerdo con lo anterior, yo problematizaría lo dicho por Fuentes en cuanto a la inexistencia de un lenguaje hegemónico. Éste, sin duda, no es visible en términos directos en las décadas presentadas, pero sí en la reacción de los escritores contra él. Asimismo, me salta un poco lo de una cultura civil o sociedad civil en Blanco y en Puga. Creo que el mercado (contexto económico) atraviesa a la sociedad civil (contexto político) en franco conflicto con el Estado, pero que la sociedad civil y sus diversos intereses, no advierte del todo los peligros y efectos del primero ni de su poderoso aparato tecnológico; o que una parte de esa misma sociedad civil es su cómplice. En las novelas del período sí se advierten los del Estado y los de los aparatos jurídicos, judiciales y burocráticos a su servicio, pero no tan claramente su relación con la institución inestable que es el mercado. La reacción es contra la hegemonía del lenguaje del poder político y la del lenguaje de los grandes sistemas de pensamiento de la cultura occidental, pero no tan claramente contra otro lenguaje hegemónico: el de los medios masivos de comunicación, sus usos y efectos. Por lo menos a reserva de una mayor investigación, así lo aprecio.

El hecho que deseo destacar es que una de las características más importantes de este período, es el uso de códigos y subcódigos sociales inestables que se interfieren entre sí. Y en relación con lo anterior, una persistente tendencia a descodificarlos desconstruyéndolos, sin posibilidad de recodificación en términos políticos y sociales (ideologías, partidos, instituciones); culturales (sistemas filosóficos, históricos, literarios, etcétera: las interpretaciones de la realidad son ambiguas sin oportunas referencias epistemológicas, estéticas y éticas). Lo mismo sucede con lo subjetivo en cuanto a modelos de conducta, roles sociales y sexuales, aspiraciones coherentes. No ignoro que, en este sentido, la novela se informa artísticamente de lo que sucede en la realidad y lo recrea; pero lo importante es que los obstáculos para la recodificación provienen también de una hegemonía sin rostro, tremendamente autoritaria, que despersonaliza y fragmenta a la sociedad civil que cada vez se parece más a una sociedad indiferenciada de consumo.

Comprendo que Puga y Blanco aluden a la capacidad de defensa y respuesta activas de dicha sociedad civil, por lo menos en el espacio literario de la producción y consumo de la "alta" cultura. Pero lo que he querido mostrar en este trabajo, entre otras cosas, es que los efectos del mercado disuelven los presupuestos de calidad en favor de la cantidad y que, en esa "maraña", la literatura ha diversificado sus funciones y universos de representación, 
pero también sus límites de pertinencia. Esto no me parece precisamente negativo, lo que me preocupa es el origen de esta especie de "entropia" que la "modernización" y sus consecuencias han producido también en la sociedad, debilitando su poder u obstaculizando la construcción de esa posible aunque relativa coherencia emocional y sensibilidad social que supone el concepto de sociedad y cultura civiles. ${ }^{17}$

El fenómeno de indiferenciación creciente en lo social y cultural, se aprecia a mi juicio en la crisis de sus códigos y en sus interferencias incapaces, así, de transmitir el patrimonio o capital simbólico que cohesiona a una sociedad. La razón de mercado, tan determinante como la razón de Estado pero diferente a ésta, no tiene centro estable de autoridad, ni opera con significaciones trascendentes - que hoy están en deuso-, por lo que destruye los códigos sociales tradicionales y los sustituye por otros individuales o grupales, casi siempre dispersos y transitorios. No obstante, en el conjunto de la narrativa de los 70 y 80 , a pesar de la indeterminación textual y a la vista de una identidad inestable, se propone la necesidad de una resignificación y refuncionamiento del código social comunitario, en el horizonte de la gran y pequeña historia que sí tienen un potencial vinculatorio. Valga este trabajo como un intento de localizar problemas, plantear posibles explicaciones y organizar tentativamente una gran cantidad de producción narrativa.

\section{Bibliografia Citada}

Aguilar Camín, Héctor. La guerra de Galio. México: Cal y Arena, 1991.

Altamirano, Carlos y Beatriz Sarlo. Conceptos de Sociología literaria. Buenos Aires: Centro Editor de América Latina, 1980.

Blanco José Joaquín. "Aguafuertes de narrativa mexicana, 1950-1980”. Nexos 56 (México, 1982).

Bourdieu, Pierre y otros. Problemas del estructuralismo. México: Siglo XXI, 1967.

Brushwood, John S. La novela mexicana (1967-1982). México: Grijalbo, 1985.

Domínguez Michael, Christopher. "Introducción". Antologia de la narrativa mexicana del siglo XX, T. II. México: Fondo de Cultura Económica, 1991, 11-73.

Dorfman, Ariel. Imaginación y violencia en América. Barcelona: Anagrama, 1972.

López González, Aralia. "La narrativa tlatelolca". Signos. México, Iztapalapa: Universidad Autónoma Metropolitana, 1987, 335-350.

"Narradoras mexicanas: utopia creativa y acción". Literatura mexicana (II)1. México: Universidad Nacional Autónoma de México, Instituto de Investigaciones Filosóficas y Centro de Estudios Literarios, 1991, 89-107.

"La vida no es un espejismo de merengue y fresa: análisis de 'Cabecita blanca' de Rosario Castellanos". De la ironía a lo grotesco. México, Iztapalapa: Universidad Autónoma Metropolitana, 1992, 127-158.

\footnotetext{
${ }^{17} \mathrm{Si}$ es que todavía puede hablarse de sociedad civil (cuyo opuesto es la sociedad anómica), cuando la esfera de lo privado está siendo invadida por la pública mediante el lenguaje hegemónico de los medios en casi todos los órdenes de la vida individual y familiar (modelo primario de socialización). Si se desmantelan las relaciones primarias, las secundarias (comunitarias y sociales) se desmantelan solas. Entonces: ¿cuál posible sociedad civil?.
} 
Marcos, Juan Manuel. De García Márquez al postboom. Madrid: Orígenes, 1986.

Molina, Javier. "Presentación la guerra de Galio". La Jornada. México, 19 de julio de 1991 , 36.

Monsiváis, Carlos. Días de guardar. México: Era, 1980. "Prólogo". A ustedes les consta (1980). México: Era, 1985, 17-76.

Pacheco, Emilio. "Muchos años después ...". Norma Klahn y Wilfrido H. Corral. Los novelistas como críticos, T. II. México: Fondo de Cultura Económica y Ediciones del Norte, 1991, 459-469.

Patán, Federico. Contrapuntos. México: UNAM, Difusión Cultural, 1989.

Puga, Maria Luisa. "Quince años de novela mexicana contemporánea". La Jornada Semanal 120. México, 29 de septiembre de 1991, 29-32.

Sefchovich, Sara. México: país de ideas, país de novelas. México: Grijalbo, 1987.

Teichmann, Reinhard. De la onda en adelante. México: Posada, 1987. 
